\title{
El Concepto de libertad política en Hannah Arendt*
}

\section{The Concept of Political Freedom in Hannah Arendt*}

\section{O Conceito de liberdade politica em Hannah Arendt*}

\section{Luis Horacio Franco Gaviria** - Chile}

Recibido el 8 de marzo de 2012, aceptado el 21 de septiembre de 2012

* El artículo corresponde a una parte del marco teórico de la investigación doctoral, cuyo título es "Una mirada al fenómeno de la migración internacional desde el concepto de libertad política en Hannah Arendt", del programa de Doctorado en Filosofía moral y política de la facultad de Filosofía de la Universidad De Chile. Investigación iniciada en marzo de 2010.

** Doctor en Filosofía moral y política de la Universidad de Chile. Magíster en Ciencia Política de la Universidad Andrés Bello en Chile. Filósofo. Docente de la Escuela de Trabajo Social de la Universidad Andrés Bello en Santiago de Chile y de la Universidad Santo Tomás en Santiago de Chile. Correo electrónico: Luishfranco2000@yahoo.com 


\section{Resumen}

Objetivo: sistematizar las ideas de libertad política en la obra de Hannah Arendt y su manera de enfrentar desde este concepto las nefastas consecuencias del Totalitarismo, lo mismo que la reivindicación del Republicanismo como sistema político de hombres virtuosos, excepcionales y libres. Metodología: consiste en una evaluación teórica de la obras de Hannah Arendt en la que se examinan conceptos tan importantes como libertad política, pluralidad, natalidad, acción, Totalitarismo y Republicanismo. A partir de esta revisión se delimitan los espacios para el desarrollo de la libertad política y se establecen las condiciones ontológicas, antropológicas, pre-políticas y políticas del concepto. Resultados: tienen que ver con la contextualización del alcance de la libertad política y los conceptos que la sustentan y la tensión agónica entre los espacios de aparición propicios para el desarrollo de la libertad política y la transformación científico-técnica que privilegió a los animales laborantes por encima de los hombres libres y de acción. Conclusiones: se advierte el peligro que representa en la época actual el Totalitarismo. Por lo mismo, aunque con influencia aristotélica, emerge el Republicanismo como un demos o comunidad política que busca revitalizar el espacio público plural, allí donde los hombres pueden crear sus propias alternativas sin tener que elegir alternativas ya creadas por la sociedad de consumo y por la artificialidad originada por la ciencia y la tecnología.

Palabras claves: libertad política, pluralidad, natalidad, acción, republicanismo.

\section{Abstract}

Objective: to systematically present the ideas of political freedom in the works of Hannah Arendt and the way she uses that concept to deal with the terrible effects of Totalitarianism as well as the claim of republicanism as a political system of virtuous, exceptional and free men. Methodology: it is a theoretical evaluation of the works of Hannah Arendt. Concepts such as political freedom, plurality, birth, action, totalitarianism and republicanism are analyzed. Based on this review, spaces for the development of political freedom are defined and ontological, anthropological, political and pre-political conditions of this concept are established. Results: the contextualization related to the reach of political freedom and its supporting concepts. Also, it deals with the agonizing tension between 
spaces of appearance favorable for the development of political freedom and the scientific and technical transformation, which favored working animals over free and action men. Conclusions: there are warnings about the danger represented by totalitarianism in this era. Likewise, although it has an Aristotelian influence, there emerges Republicanism as a demos or political community, which seeks to revitalize the plural public space; it is there where men can create their own alternatives without having to choose alternatives ready-made by the consumer society and the artificiality generated by science and technology.

Keywords. Political freedom, plurality, birth, action, republicanism.

\section{Resumo}

Objetivo: sistematizar as ideias de liberdade política na obra de Hannah Arendt e sua maneira de enfrentar desde este conceito as nefastas consequências do Totalitarismo, o mesmo que a reivindicação do Republicanismo como sistema político de homens virtuosos, excepcionais e livres. Metodologia: consiste em uma revisão teórica da obra de Hannah Arendt na que se examinaram conceitos tão importantes como liberdade política, pluralidade, natalidade, ação, Totalitarismo e Republicanismo. A partir desta revisão se limitaram os espaços para o desenvolvimento da liberdade política e se estabelecem as condições ontológicas, antropológicas, pré - políticas e políticas do conceito. Resultados: tem que ver com a contextualização do alcance da liberdade política e os conceitos que a sustentam e a tensão agônica entre os espaços de aparição propícios para o desenvolvimento da Liberdade política e a transformação cientifica - técnica que privilegiou aos animais trabalhadores por em cima dos homens livres e de ação. Conclusões: adverte se o perigo que apresentam na época atual o Totalitarismo. Pelo mesmo, porém cm influencia aristotélica, emerge o Republicanismo como um demos ou comunidade política que procura revitalizar o espaço publico plural; ali onde os homens podem criar suas próprias alternativas sem ter que eleger alternativas já criadas pela sociedade de consumo e pela artificialidade gerada a partir da ciência e a tecnologia.

Palavras chaves: liberdade política, pluralidade, natalidade, ação, republicanismo. 


\section{Introducción}

La obra de Arendt contiene por lo menos dos aspectos claves: por un lado, tiene una fuerte inquietud filosófica y política y, por otro lado, una experiencia de vida inspiradora que no le permitieron a la autora mirar la historia con la neutralidad y objetividad que algunos de los críticos le reclamaron. Del primer aspecto, se puede decir que su encuentro en Marburgo en 1921con Heidegger, marcó definitivamente su pensamiento, no sólo por los planteamientos de éste, en quien reinaba una profunda idea de crisis de la humanidad, sino por la corta militancia de Heidegger en el partido nacional socialista, hecho que la llevó a cuestionarse la verdadera utilidad de la filosofía en la Polis. En 1925, en Heidelberg, Arendt comenzó a trabajar su tesis doctoral con Karl Jaspers, con quien conservó una profunda amistad.

El segundo aspecto en que se enmarca la obra de Arendt, tiene que ver con las horrorosas experiencias vividas en la Alemania Nazi y las consecuencias de la Segunda Guerra Mundial. Es importante entenderla en la contingencia para comprender su pensamiento. Para recordar, su contingencia fue la Alemania Nazi, los campos de concentración, su condición de apátrida y el Totalitarismo, ante lo cual no puede existir ni objetividad ni imparcialidad, pues una interpretación objetiva es no entender nada de lo ocurrido (Arendt, 2006). Anne Amiel (2007) por su parte, cuando menciona algunos aspectos metodológicos de la obra de Arendt (2006), considera que la imparcialidad aleja de los hechos y de la posibilidad de describirlos y de comprenderlos tal como ocurrieron; así, describir, por ejemplo, los campos de concentración con objetividad, es perdonar en parte lo que allí sucedió (p. 12).

En consecuencia, los elementos vivenciales en la obra de Arendt resultan novedosos para el análisis de los hechos políticos del siglo XX y desde la particular mezcla entre intelectualidad y experiencia que le han permitido a Arendt escapar de esquemas absolutamente filosóficos o absolutamente políticos, este trabajo pretende ser un acercamiento al concepto de libertad política en Hannah Arendt, entendido como el espacio establecido por muchos y en el que cada cual se mueve entre iguales. Por eso, dice Arendt "quien domina sobre los demás y es, por principio, distinto de ellos, puede que sea más feliz, y digno de envidia que aquellos a los que domina, pero no más libre" (2005, p. 153). Se trata de un concepto que toma vida en otros dos conceptos fundamentales; por un lado, la pluralidad de los hombres, iguales en el diálogo y diferentes en cuanto a las

140 percepciones que tienen del mundo, y por otro lado, en la natalidad, como po- 
sibilidad de comenzar algo nuevo. El concepto de libertad política en Arendt se presenta como un concepto polisémico que permite a sus lectores penetrar diferentes contextos históricos, con el objetivo de hacer frente a la dominación total para conservar, lo que ella ha llamado en La promesa de la política el milagro de la libertad (2005, p. 149).

Llama la atención que a pesar de estar frente a un concepto que recorre toda su obra, Arendt no lo elabora como teoría, sino que lo plantea para abrir una discusión, explicitado en algunos capítulos de sus textos como en el libro Entre el pasado y el Futuro, donde le dedica 30 páginas, un aparte de La vida del espíritu, un artículo titulado "Los Derechos públicos y los intereses privados" en respuesta al de Charles Frankel titulado Los Derechos privados y el bien público, así como también, una profunda reflexión acerca de la relación entre política y libertad desarrollada en su texto La promesa de la política, reflexión que sirvió de base para el texto ¿Qué es la Política?, donde se pregunta por el sentido de la política y cuya respuesta es contundente: "El sentido de la política es la libertad" (Arendt, 2005, p. 144).

No obstante, su obra es una reivindicación de los espacios públicos donde los hombres ejercen su libertad política y cuyo interés crece por la amenaza del Totalitarismo, capaz de destruir cualquier resquicio de la libertad humana. En textos tan importantes como Origenes del Totalitarismo de 1951, La Condición Humana de 1958, Entre el pasado y el Futuro de 1961, Eichmann en Jerusalén de 1961, Sobre las Revoluciones de 1963, Sobre la Violencia de 1970 y La Vida del Espiritu de 1978, entre otros, se puede notar que el hilo conductor de su preocupación y rechazo por la dominación es el sentido positivo de la libertad como respuesta a los movimientos totalitarios; es en definitiva, una lucha contra el movimiento totalitario que buscó y sigue buscando la total superficialización de los hombres laborantes.

Para cumplir con el objetivo de este trabajo sobre el concepto de libertad política en la obra de Hannah Arendt a continuación se expondrá la dimensión ontológica de la libertad política, heredada de los dos principios ontológicos de la política: La pluralidad (2010, p. 43), entendida como el entre que se da entre iguales, por un lado y diversos, por el otro; y La natalidad, como el inicio que da vida a cada ser y lo hace libre para comenzar algo nuevo. Ambos principios inherentes al ser humano, permiten que algo nuevo acontezca en el mundo, pues se trata de un mundo que no puede ser pensado de forma determinista con un orden de leyes, sino por el contrario, como un espacio abierto y cam- 
biante que todos los seres humanos pueden compartir. Por lo mismo, tanto la pluralidad como la natalidad, en la obra de Arendt, serán condiciones ontológicas y pre-políticas a partir de las cuales se podrá construir la vida política como espacio de libertad.

También se mostrará la jerarquía que se da al interior de la vida activa entre Labor, Trabajo y Acción. El resultado de dicha jerarquía permite dejar de lado la dimensión ontológica para entrar en una dimensión antropológica o de experiencia humana, pues como lo expresa Arendt en su texto De la Historia a la Acción "La vida activa no es solamente aquello a lo que está consagrada la mayoría de los hombres, sino también aquello de lo que ningún hombre puede escapar totalmente, porque está en la condición humana que la contemplación permanezca dependiente de todos los tipos de actividades" (2005, p. 89). Desde esta perspectiva, la acción toma el lugar que en los griegos tenía la contemplación y se convierte en principio de libertad. Así, la acción "es como un recordatorio siempre presente de que los hombres, aunque han de morir, no han nacido para eso, sino para comenzar algo nuevo y ese comenzar algo nuevo no es otra cosa que la garantía de la libertad en la tierra" (2005, p. 107).

Este trabajo también busca volver sobre el Republicanismo como el espacio que posibilita la aparición de los hombres donde no sólo pueden pensar, juzgar y expresar sus ideas, sino que además pueden evitar que les arrebaten la libertad, de gozar de pequeños espacios de privacidad, pues a pesar de la tensión que Arendt muestra entre el Republicanismo y el Liberalismo, no deja de reconocer algunos logros políticos del Liberalismo, sobre todo los que tienen que ver con los derechos de las personas y los organismos legales. De alguna manera la República contemporánea reemplaza a la Polis griega y va más allá; según Canovan, citada por María José López "la vida de los seres humanos está en peligro por la transformación científico-técnica, lo que hace necesaria la recuperación de las instituciones capaces no sólo de construir un espacio público plural donde la comunidad humana se desarrolle, sino la posibilidad de que esa comunidad humana se manifieste libremente" (2006, p. 133). Por último, cuando se habla de República en Arendt, se habla de una organización política libre, donde la cosa pública es posesión y dominio de los ciudadanos, plurales e iguales. Es decir, República es el gobierno de los ciudadanos en el 142 que cada uno es señor de sí mismo. 


\section{Metodología}

Consiste en una revisión teórica de la obras de Hannah Arendt en la que se examinan conceptos tan importantes como libertad política, pluralidad, natalidad, acción, Totalitarismo y Republicanismo. A partir de esta revisión se delimitan los espacios para el desarrollo de la libertad política y se establecen las condiciones ontológicas, antropológicas, pre-políticas y políticas del concepto. Dentro del recorrido conceptual se detallan algunas distinciones importantes en la obra de Arendt y se explicita como desde la libertad política se enfrentan las nefastas consecuencias del Totalitarismo.

\section{Resultados}

\section{La dimensión ontológica de la libertad política}

En el artículo ¿Qué es la libertad? publicado en su libro Entre el pasado y el Futuro. Ocho ejercicios sobre la reflexión política (1961), Arendt advierte que preguntarse por la libertad parece ser una empresa sin esperanza, pues es tratar de entender algo así como la cuadratura del círculo o superar la eterna tensión entre la conciencia que dice que se es libre y el consciente que muestra una orientación de las acciones desde el principio de causalidad. Así, dice Arendt, la libertad resulta ser un espejismo cuando la psicología observa lo que, supuestamente, es su campo más recóndito, y lo que se pone en juego es una enorme cantidad de causas, factores y motivaciones que en muchos casos, aún se encuentran ocultas en la naturaleza de cada individuo y que la mente tendrá que hacer un enorme esfuerzo para poner en orden todos sus elementos que saldrán a la luz según las exigencias de las propias experiencias (1996, p. 155).

Esto significa, de algún modo, que la idea de libertad se disuelve en el pensamiento mismo, por lo que para Arendt la idea de libertad interna, como libertad moral, no tendrá tanta relevancia como la libertad que se pone en práctica, en el espacio público donde los individuos confluyen, pues no se trata de quedar entrampados en una situación interior, de pensamiento y voluntad, sino de salir a un campo que se construye entre los hombres y se renueva desde ahí. Es decir, no en términos de Isaiah Berlin, sino en sus propios términos, encontramos aquí dos conceptos de libertad: el primero, se refiere a la libertad moral y corresponde, como ya se ha dicho, al campo interno de la mente humana que está gobernada por la razón y la voluntad. Esta libertad, dice Arendt en La vida del Espiritu, se ubica en un terreno 
pre-político; mientras que el segundo concepto de libertad, corresponde a la libertad política y se brinda en el espacio construido entre los hombres y precisa, entre otros elementos, de la acción y la política.

La libertad política, que se muestra en un principio contraria a la libertad moral, irrumpe en la conciencia de los hombres para evitar que estos se aíslen del mundo y se conviertan en seres irrelevantes para la sociedad, pues la libertad moral sirve como refugio a aquellos que no encontraron un lugar en el mundo y por lo tanto, afirma Arendt (1996, p. 158) carecieron de una condición mundana; la que todos consideraron, casi hasta mediados del siglo XIX, como el requisito para la libertad. De este modo, continúa Arendt "Los argumentos más persuasivos para la superioridad absoluta de la libertad interior se pueden encontrar aún en un ensayo de Epicteto, que empieza por determinar que es libre aquel que vive como quiere" (1996, p. 159).

Epicteto, dice Arendt, demuestra que el hombre es libre si tiene dominio de lo que se presenta a su alcance y por lo mismo, lo exterior es marginado en la medida en que cada hombre lo considere conveniente; sin embargo, los hombres no sabrían nada de la libertad interior, si antes no tienen la experiencia tangible y mundana de ser libres en los espacios de aparición. En consecuencia, Arendt le otorgará mayor importancia a la libertad política y dejará en un segundo plano la libertad moral o filosófica.

Así, la libertad política se distingue de la libertad filosófica al ser claramente la cualidad del yo puedo y no del yo quiero; y en la medida en que es poseída por los ciudadanos más que por los hombres en general, sólo puede manifestarse en las comunidades.

De esta manera, insiste Arendt, la libertad política no es un fenómeno que dependa de la voluntad sino de la palabra y la acción puestas en una escena común, con el objetivo de dar existencia a algo que no existía antes y por lo mismo libre de motivaciones y de fines; así, la fuerza de la libertad dependerá de las circunstancias cambiantes del mundo y de lo que los hombres puedan construir según ciertos principios. La libertad está libre de la razón y de la voluntad y ahora está lista para actuar, ni antes ni después, porque ser libres y actuar, señala Arendt (1996) es la misma cosa.

De este modo, entender el concepto de libertad política en Arendt permite entender las múltiples y enriquecedoras distinciones encontradas en su obra, 144 como por ejemplo, las hechas entre la vida activa y la vida contemplativa, lo 
público y lo privado, el republicanismo y el liberalismo político, la revolución y la violencia o la violencia y el poder, la palabra y la acción, la acción y el trabajo, militancia y participación, libertad moral y libertad política, totalitarismo y dictadura, culpa y responsabilidad, juicios y pre-juicios; así como también la responsabilidad individual y colectiva, entre muchas otras distinciones fundamentales para delimitar el alcance de cada una de sus ideas y demarcar los terrenos de la libertad política. Esta demarcación, más allá de todas estas distinciones, debe partir por la búsqueda de los elementos fundamentales para la libertad política, es decir, por la búsqueda de aquello sin lo cual la libertad política no puede ser.

Desde lo que Arendt llama "espacio de aparición", donde los hombres se encuentran o aparecen y se hacen visibles, existen por lo menos dos elementos que hacen que este aparecer ante otros se dé; por un lado, la pluralidad y por otro la natalidad. Ambos conceptos no sólo aplican a lo político, sino también a la libertad y dada la importancia de estos conceptos en la obra de Arendt y para el desarrollo de este trabajo, vale la pena detenerse brevemente en cada uno de ellos.

\section{La pluralidad}

La pluralidad es un concepto cardinal en la obra de Hannah Arendt, no sólo porque opera como fundamento de lo político y de la libertad de los individuos, sino también porque le permite a la autora cuestionar el concepto de Hombre universal, absoluto y abstracto que muestra en cada individuo la copia de aquel modelo determinado por las necesidades de su naturaleza, cuando lo que existe realmente es una diversidad de seres que aparecen y se rodean de otros que igualmente pueden ser percibidos; pues, si es cierto que los hombres existen en un mundo sensible en la medida en que se muestran y son percibidos en todos sus aspectos, entonces también es cierto que se requiere de una pluralidad de hombres, pueblos e instituciones que le den sentido a cada una de las manifestaciones humanas.

Por lo mismo, es necesario entonces derrumbar el concepto de Hombre absoluto e invertir la jerarquía metafísica de lo que es y lo que aparece, ya que cada individuo se muestra de diversas formas en un mundo donde el ser y el aparecer coinciden. En otras palabras, dice Arendt "Nada de lo que es, existe en singular desde el momento en que hace su aparición; todo lo que es está destinado a ser percibido por alguien. No es el Hombre en mayúscula, sino la totalidad de los hombres los que habitan el planeta. La pluralidad es la ley de la tierra" (2010, p. 43).

Para $\quad$ Franco Gaviria, Luis Horacio (2013). El Concepto de libertad política en Hannah Arendt. 
Así, no sólo existe la pluralidad de los que son percibidos sino de los que perciben y de cuya confrontación surge un espacio de interacción y de diálogo que va configurando el mundo donde la pluralidad encuentra su lugar, sin tener que elevarse a otros mundos donde los filósofos de la antigüedad pretendieron encontrar la verdad única y no compartida. A partir de aquí, se podrá entender que hasta el pensamiento en soledad presupone esta condición ontológica de la pluralidad; el dos en uno socrático que revela el miedo a la contradicción, por un lado, y la necesidad de estar de acuerdo con uno mismo, por otro lado, plantea que los hombres, cuando piensan, están de alguna manera hablando consigo mismo como si hablaran con un amigo. Así, dice Arendt

Esta es también la razón de que la pluralidad de los hombres nunca pueda abolirse enteramente y de que la huida del filósofo del reino de la pluralidad siempre permanezca como una ilusión (...). El filósofo, quien, tratando de escapar de la condición humana de la pluralidad, emprende esta huida a la soledad absoluta, está abocado más radicalmente que ningún otro a esta pluralidad inherente a todo ser humano, puesto que es la compañía con los otros lo que, al sacarlo del diálogo del pensamiento, se hace uno nuevo: un ser humano singular y único, habla con una sola voz y que es reconocible como tal por los demás (2008, p. 58).

Ahora bien, dicho reconocimiento plantea que la pluralidad humana tiene un doble carácter de igualdad y diversidad. Tal como lo expresa Cristina Sánchez (1994):

$\mathrm{Si}$ los hombres no fueran iguales no podrían entenderse ni planear y prever para el futuro las necesidades de los que llegarán después. Si los hombres no fueran distintos, es decir, cada ser humano diferenciado de cualquier otro que exista, haya existido o existirá, no necesitarían el discurso ni la acción para entenderse. Signos y sonidos bastarían para comunicar las necesidades inmediatas e idénticas (p. 23).

Desde esta perspectiva, la pluralidad no sólo es diversidad sino también igualdad y más allá de la victoria del mundo moderno que habla de una igualdad como el reconocimiento legal y político, se trata más bien de una conquista de la esfera pública de parte de los hombres, donde la distinción y la diferencia no necesariamente son asuntos privados. Así, la Polis, dice Arendt (2005):

Estaba calada de un espíritu agonal, donde todo individuo tenía que distinguirse constantemente de los demás, demostrar con acciones únicas o logros, que era el mejor. Dicho con otras palabras, la esfera estaba reservada a la individualidad; se trataba del único lugar donde los hombres podrían mostrarse real e invariablemente quiénes eran (p.64). 
Esto significa que la igualdad es la posibilidad que cada individuo tiene para mostrarse en el espacio público y desde allí cada quien va forjando su individualidad y su identidad. Por esto mismo, para Arendt es imposible definir al Hombre con mayúscula, porque se le vería como un "que" privado de un "quien" que en el espacio público construye su identidad en la medida en que es percibido por los demás y en ese sentido los hombres realizan su máximo esfuerzo cuando se saben contemplados por otro que es la máxima subjetividad individualizante. Dice Arendt que "Sin tales otros, que son mis iguales, no hay libertad. Por eso quienes dominan sobre los demás y es, pues, distinto de ellos, puede que sea más feliz y digno de envidia que aquellos a los que domina pero no más libre" (2007, p. 70).

Queda claro que la igualdad de los hombres no es sólo ante la ley o que la ley se aplique a todos por igual, sino más bien, lo que los griegos llamaron Isonomía o la libertad de hablar los unos con los otros; se trata en el fondo de la libertad de la palabra, negada en Grecia a los esclavos y a los bárbaros, pero otorgada como un privilegio a los ciudadanos que podían expresar sus diferencias y debatir con libertad.

Desde esta perspectiva, en Arendt se encuentra otro concepto que es de mucho valor, pero para efectos de este artículo solo se hará mención: Sentido Común, que correctamente definido en su obra, es:

Atestiguarse ante los demás y poner en evidencia la mente humana que sale de sí misma y se pone en contacto con la realidad, lo que implica de paso que la libertad política es mundana y requiere de un espacio para que los hombres hagan su aparición", así, continúa Arendt "Lo decisivo de esta libertad política es su vínculo a un espacio. Quien abandona su Polis o es desterrado pierde no solamente su hogar o su patria sino también el único espacio en que podía ser libre; pierde la compañía de los que eran sus iguales" (2007, pp. 70-71).

Evidentemente no existe otra forma de entender la libertad en Hannah Arendt, sino vinculada directamente a la política y en ese sentido, cualquier concepto de libertad que se lea desde su obra ha de tener esta connotación. Por ejemplo, la libertad de movimiento, la libertad de expresión o la libertad como espontaneidad, se dan a partir de un espacio real de aparición, donde los demás me atestiguan; no obstante tratarse de una idea muy clara y recurrente en la obra de Arendt, parece que la libertad de movimiento y la de expresión requieren de menos explicación que la espontaneidad; concepto que tiene que ver con la creatividad de cada ser libre y con la posibilidad de empezar algo nuevo. En este 
punto se hace necesario detenerse en el segundo concepto de la dimensión ontológica de la libertad política como el concepto de Natalidad.

\section{La Natalidad}

La natalidad en Arendt se entiende como la posibilidad de iniciar algo nuevo y es una cualidad de cada ser humano que vive y comparte un espacio real en el mundo; así, la Natalidad, como principio ontológico de la libertad política le permite a Arendt reafirmarla como una cualidad que sólo se da en el mundo y en los hombres de acción que lo habitan. Por lo mismo, la pluralidad de los individuos no sólo se enmarca en la forma de expresarse y actuar ante los demás, sino también desde lo biológico, ya que las generaciones se remplazan unas a otras. Desde esta filosofía de la vida, muy a pesar de su destino final, el hombre encuentra su salvación en su nacimiento, es decir, que el milagro que salva al mundo de su ruina natural, según Arendt es en último término el hecho de la Natalidad, en el que se enraíza ontológicamente la facultad de la acción (2009, p. 290).

Esta condición, común a todos los mortales y que consiste en la capacidad de iniciar algo nuevo, permite que el pensamiento discurra libremente y que el hombre actúe sin responder a formas prefiguradas en el mundo. Insistir en el determinismo científico es empeñarse en negar la libertad humana. Lo absoluto es el inicio, el comienzo de una nueva secuencia de seres y hechos no prefigurados y por lo tanto, no previsibles. Arendt en su ensayo ¿Qué es la libertad? menciona el fundamento ontológico de la Natalidad: "En la esencia de todo nuevo comienzo está el que se abra paso en el mundo con una "improbabilidad infinita"(1996) y, sin embargo, esta infinita improbabilidad es lo que de hecho constituye la textura de todo cuanto llamamos real. La existencia descansa, después de todo, en una cadena de milagros: origen de la tierra, desarrollo de la vida orgánica en ella, evolución de la humanidad partir de las especies animales.

El milagro de la natalidad, como fundamento de la libertad política que se concreta en la acción, encarna al mismo tiempo el principio y el fin de toda acción y para liberar el concepto de todo prejuicio, afirma Arendt que conviene tener presente que el marco completo de la existencia real y de todo lo que vive en la tierra es ya un milagro y desde el punto de vista de los procesos...construye una cadena de improbabilidades infinitas que se vuelven de alguna manera tan cotidianas que hablar de milagro suena extraño" (2008, pp. 149-150). Visto este fenómeno desde fuera resulta milagroso, pero lo es más cuando se necesita de 
un Quien para hacer que esos milagros ocurran. Los hombres tienen por don, el milagro de la acción, que no sólo pone en marcha un nuevo comienzo -archeinsino que desencadena todo un nuevo proceso -agere.

En resumen, se puede afirmar que tanto la Pluralidad como la Natalidad le permiten a cada individuo comenzar a gozar de los espacios públicos construidos para la libertad política; y por la condición ontológica de ambos conceptos (Pluralidad y Natalidad), Arendt los ubica en un espacio pre-político, como condición humana sin la cual ninguna acción humana puede ser. Esto significa que todo ser humano tiene el derecho a esperar milagros, dice Arendt, no porque creamos en ellos sino porque los hombres, en la medida en que pueden actuar, son capaces de llevar a cabo lo improbable e imprevisible y de llevarlo a cabo continuamente, lo sepan o no (2005, p.150).

\section{La dimensión antropológica de la libertad política}

Para entender el carácter mundano de la libertad política en la obra de Arendt, es necesario entender rápidamente, la jerarquía que se da en el mundo antiguo entre la vida activa y la vida contemplativa y la posterior inversión que Arendt hace de estos dos ámbitos de la vida humana, pues no sólo busca recuperar la dignidad de la política como una acción humana en el espacio público, sino también, mostrar la utilidad de la filosofía en la Polis. Esto permitirá de paso reforzar el argumento expuesto arriba, en el sentido de que la libertad política se da entre hombres (pluralidad), distintos e iguales y que goza de un espacio y un tiempo determinado por la doble condición de la pluralidad, como un entre que se construye y dinamiza desde la vida misma y escapa del determinismo de la naturaleza, por un lado y al absoluto creado desde la razón por el otro.

Cuando Arendt, en la entrevista con Gunter Gauss en 1964, afirmó que no quería ser filósofa y que prefería ser una teórica de la política, lo que buscaba con esto era adoptar una vía experimental para la filosofía en consonancia con la política; pues ella jamás, o por lo menos su obra no lo refleja, intentó hacer una separación de dos mundos como bien lo hicieron los griegos a partir de Platón y buena parte de la tradición occidental, como si pensar significara desaparecer del mundo real y tomar distancia con lo común que puede tener el mundo para los hombres. La burla de la criada Tracia cuando Tales de Mileto, quien por mirar al cielo se olvidóver lo que hay en la tierra, ejemplifica perfectamente el distanciamiento de los filósofos con los espacios de aparición. Arendt por su parte, cuando recuerda la torpeza del pensador ausente [desconectado], comienza a 
buscar la fórmula para acabar, por un lado, con la torpeza del pensador cuando interviene en la Polis y por otro lado, acabar con la distancia entre el mundo de los hombres y el construido para los pensadores profesionales, claramente apolítico y amundano, como si pensar se tratara de una prerrogativa de pocos, cuando, realmente, dice Arendt, es una característica de los hombres que viven en un mundo plural. Dejar las cosas en el tono apolítico, significa que la libertad de pensamiento es la libertad que tiene cada hombre de retirarse o alejarse del mundo, cuando de lo que se trata es de reivindicar la libertad de movimiento, de expresión y de acción como la expresión de los hombres que se mueven, dialogan y actúan y tiene el coraje de moverse y potenciarse en espacios públicos como una condición indispensable para la acción.

Sin embargo, si el riesgo de la apoliticidad es ver cómo cada individuo se retira del mundo, en el otro extremo del camino también se encuentra un riesgo que no es menor, como la tendencia a creer que todo lo público es político y que en aras de evitar la retirada del individuo a su propio espacio privado, se ha querido convertir lo privado en público. El esfuerzo de Arendt para tratar de devolverle la dignidad a la política se concentra en delimitar su alcance para que allí se desarrolle y viva la libertad de los hombres. En este sentido, la política debe resguardarse, además, de la economía, pues se sabe que la economía es una dimensión que permite ordenar lo doméstico y administrar los bienes escasos en el hogar, aquellos que, en términos de Arendt, no permiten el ejercicio de la libertad política. Por lo mismo, la distinción entre labor, trabajo y acción, permitirá entender que los dos primeros niveles están resguardados para el desarrollo individual de los hombres mientras que el tercero, es decir, la acción, será el espacio por excelencia en el que los hombres pueden desarrollar su libertad política, una libertad que escapa en todo sentido a las necesidades de los hombres.

En La Condición Humana (1958), se contempla una jerarquía antropológica entre labor, trabajo y acción, tres conceptos que pertenecen a lo que los antiguos llamaron vida activa y que Arendt pretende reivindicar frente al desprecio que esta vida tuvo en los griegos. Sin embargo, lo que intentó hacer la autora en su libro no fue fácil, pues aparte de tener que luchar contra una metafísica de la tradición filosófica, tuvo que entrar en una serie de precisiones en torno al marxismo, ya que para estructurar su pensamiento contra el Totalitarismo, la tesis de que los filósofos en vez de interpretar el mundo deben transformarlo, resultó desafortunada, pues termina privilegiando a los hombres de labor y de trabajo y no a los hombres de acción. Así pues, Arendt

150 al invertir la jerarquía de la antigua Grecia y poner la vida activa por encima de 
la vida contemplativa, creó una estructura que pone la acción por encima de la labor y del trabajo; así, la acción es concebida como una praxis revolucionaria que no se subordina a ningún fin ulterior.

Antes de mirar con detenimiento la labor, el trabajo y la acción y lo que implica para la libertad política, es preciso señalar la crítica que Arendt hace de la obra de Marx y cómo llega a la conclusión de que definitivamente su lucha por el proletariado, no fue una lucha por la libertad, pues de la misma manera como el animal laborans fue excluido en la antigüedad de la esfera pública, el homo faber, en la modernidad, es excluido de la vida política, que no necesariamente es la misma vida pública, ya que el ascenso de la vida privada hacia la vida pública generó un auge de la vida social que amenazó el "Esplendido aislamiento" del trabajador, quien en algún momento quiso, sin éxito alguno, mediante el mercado, recibir el estímulo del reconocimiento y estrechar los lazos de amistad. De esta manera, al trabajador no le quedó más que la posibilidad de relacionarse con los otros a través de los productos fabricados en el aislamiento. En esta línea, Arendt (2005) afirma que:

Históricamente, la última esfera pública, el último lugar de reunión relacionado al menos con la actividad del homo faber, es el mercado de cambio en el que exhibe sus productos. La sociedad comercial, característica de las primeras etapas de la época moderna o del comienzo del capitalismo, surgió de esta 'conspicua producción' con su concomitante apetito de universales posibilidades de trueque (p. 185).

Desde esta perspectiva, continúa Arendt (2005):

La actividad pública en una sociedad de mercado no es más que el intercambio de productos y sus mayores valores son los de las máquinas que elevaron la productividad de los hombres y le fueron arrebatando poco a poco su humanidad. Dicho en otras palabras, los valores, a diferencia de las cosas, actos o ideas, nunca son los productos de una específica actividad humana (p. 187).

Ni Marx ni la introducción de la maquinaria fueron capaces de eliminar el hecho de que el hombre se ve obligado a trabajar para vivir, de que el trabajo es, por tanto, no una actividad libre y productiva sino que está ligado inextricablemente a las necesidades que acarrea el simple hecho de estar vivo. En palabras de la autora, "El gran logro de Marx fue hacer del trabajo el centro de su teoría, pues el trabajo era exactamente aquello respecto de lo cual había desviado su mirada toda la filosofía política una vez que ya no osaba justificar la esclavitud" (Arendt, 2008, p. 117). Con Marx, la tradición 
del pensamiento político occidental se rompió y el resultadode este proceso condujo a la reinterpretación de todas las actividades humanas, como actividades de la labor y del trabajo.

Lo decisivo [en la obra de Marx] no fue la emancipación política de la clase trabajadora y la igualdad de todos que, por primera vez en la historia, incluye a los trabajadores domésticos. Lo decisivo fue más bien la consecución de que a partir de ahora la labor como actividad humana dejó de pertenecer al espacio estrictamente privado de la vida: la labor [y el trabajo] se convirtió en un hecho público político de primer orden (Arendt, 2007, p. 26).

En síntesis, parece que Marx, al igual que muchos otros filósofos, olvidaron la distinción entre labor y trabajo, con lo que fueron dejando por fuera las características que las distinguió en la Antigüedad y en la modernidad. En la Distinción de la labor con el trabajo, dice Arendt, se encuentra de nuevo el tiempo, concepto fundamental para entender mejor en su obra, la vida activa y la articulación entre labor, trabajo y acción.

\section{La labor}

En el primer capítulo de La Condición Humana, Arendt expresa que las tres actividades fundamentales de las condiciones básicas del hombre en la tierra, son la labor, el trabajo y la acción. La primera de ellas, la más básica o elemental y que corresponde al proceso cíclico de la vida misma, está definido como "Actividad correspondiente al proceso biológico del cuerpo humano, cuyo espontáneo crecimiento, metabolismo y decadencia final están ligados a las necesidad vitales producidas y alimentadas por la labor en el proceso de la vida. La condición humana de la labor es la misma vida" (Arendt, 2005, p. 35).

La idea de que la condición humana de la labor es la más básica de las acciones humanas, no es una idea nueva y proviene del desprecio que los griegos tenían del animal laborans, no como artesano sino más bien como esclavo. En Grecia la esclavitud estaba instituida por la necesidad de mantener la vida misma, lo que significa que los esclavos de la labor, lo eran por las necesidades vitales. En este sentido y a diferencia de la visión que los historiadores modernos tienen de la esclavitud, no se trataba de la explotación o de un trabajo barato en beneficio del dueño, sino más bien de excluir la labor de las condiciones de la vida del hombre; efectivamente, los griegos hablaron del animal laborans como la especie animal más elevada que puebla la tierra, capaz de laborar con su cuerpo, diferente al homo faber que trabajan con sus

152 manos (Arendt, 2005, p. 110). 
La gran confusión de términos que se produjo en la modernidad y a la que Marx no escapó, se debió a la idea de que el animal laborans puede elevar su productividad en beneficio de la burguesía y la acumulación de capitales. Desde ahí y sólo desde ahí, la labor fue borrando los límites con el trabajo y su emancipación significó la emancipación de otras clases que quedaron libres de la opresión y la explotación. La gran virtud de este fenómeno producido en la modernidad fue el progreso a hacia la no-violencia, aunque no necesariamente hacia la libertad, pues hay que recordar que en la modernidad tanto los trabajadores como los laborantes pudieron salir al espacio público para emprender la lucha entre los burgueses y el proletariado, sin que por esto se garantizara la libertad política, pues la lucha nunca dejó de tener el objetivo de la igualdad de todos en cuanto a cubrir sus necesidades básicas.

\section{El Trabajo}

Está definido por Arendt (2005) como:

La actividad que corresponde a lo natural de la exigencia del hombre, que no está inmerso en el constante repetido ciclo vital de la especie, ni cuya mortalidad queda compensada por dicho ciclo. El trabajo proporciona un "artificial" mundo de cosas, claramente distintas de todas las circunstancias naturales. Dentro de sus límites se alberga cada una de las vidas individuales, mientras que este mundo sobrevive y trasciende a todas ellas. La condición humana del trabajo es la mundanidad (p. 35).

Desde esta definición, la mundanidad de la condición humana logra un carácter duradero que supera el ciclo vital, cuyo campo está ocupado por la labor. Se trata de fabricar cosas con un carácter duradero que sirva para albergar a los hombres en el mundo y además entregarle una cierta objetividad expresada en el uso de todo aquello que es capaz de fabricar y con lo que será identificado. De esta manera, los hombres se convierten en amos, dueños y señores de la naturaleza, lo que les permite ejercer una violencia excesiva hacia ella y emprender el camino de la destrucción, ya que en la fabricación no existe la necesidad de repetir los procesos. Esto significa que la fabricación tiene un comienzo determinado y un fin determinado que puede dejar a los hombres sin trabajo, llevándolos a la necesidad de querer destruir lo hecho con sus propias manos para hacerlo nuevamente, pues no sólo tiene que ratificar que es dueño y señor de la naturaleza, sino que además, creerse libre para hacer y para destruir, ya que la misma determinación de medios y fines de la fabricación, elimina la creatividad propia de la natalidad, donde 
siempre se puede comenzar algo nuevo sin saber los resultadosy cierra los espacios para la espontaneidad como expresión de libertad política, pues cada elemento fabricado dura considerablemente más tiempo que el utilizado en la creación y entonces lo que queda de valor en el objeto fabricado es su utilidad y su posibilidad de cambio, quedando atrapado en una interminable cadena de medios y fines sin llegar nunca a un principio que pueda justificar la categoría de utilidad misma (Arendt, 2005, p.101).

\section{La acción}

El concepto de acción en Arendt (2005) es tan rico y polivalente como la libertad misma, pues de alguna manera su obra se justifica en la medida en que la acción de los hombres se soporta en la libertad política y la convivencia humana, como el ser con otros en el mundo. Así, la acción:

Puede estimularse por la presencia de otros cuya compañía deseemos, pero nunca está condicionada por ellos; su impulso surge del comienzo, que se adentró en el mundo cuando nacimos y al que respondemos comenzando algo nuevo por nuestra propia iniciativa. Actuar, en sentido más general, significa tomar una iniciativa, comenzar (como indica la palabra griega archein, "comenzar", "Conducir" y finalmente "gobernar") poner algo en movimiento (que es el significado originalmente latino). Debido a que son initium los recién llegados y principiantes, por virtud del nacimiento, los hombres toman la iniciativa, se aprestan a la acción (pp. 206-207).

En este sentido, es la acción la única actividad que se da entre los hombres dentro de la vida activa, sin la mediación de materiales o cosas y que aparece con la natalidad y desaparece con la muerte. Es la acción, en palabras de Arendt, la que permite que los hombres entren en el juego de crear nuevos discursos y nuevos espacios de aparición y donde su grandeza sólo puede basarse en su propia realización, y no en su motivación o en su logro (2005, p. 231). Esto implica que cada hombre en su acción se va confirmando a sí mismo, pues a pesar de que el discurso y la acción son más fútiles que la materia, la acción posee una cualidad propia como es crear su propia memoria.

La convicción de que lo más grande que puede lograr el hombre es su propia aparición y realización no es cosa natural. Contra esta convicción se levanta la del homo faber al considerar que los productos del hombre pueden ser más duraderos que el propio hombre, y también la firme creencia del animal laborans de que la vida es el más elevado de todos los bienes. Por lo tanto, ambos son apolíticos, estrictamente hablando, y se inclinan a denunciar la acción y el discurso como ociosidad...y por lo general juzgan las actividades 
públicas por su utilidad con respecto a fines supuestamente más elevados: Hacer el mundo más útil y hermoso en el caso del homo faber, hacer la vida más fácil y larga en el caso del animal laborans (Arendt, 2005, p. 233).

En ese sentido, todas las personas que se reúnen en el mercado, no son personas sino productores y su relación está mediada por lo producido, donde su público está cautivado por la apetencia de lo producido y no por la fuerza del discurso y la acción de las personas, pues cada acción tiende a generar una reacción distinta, creadora, innovadora en cuyo caso el proceso se extienda hasta el infinito. No es gratuito, que los hombres, históricamente hayan necesitado un espacio para sus reuniones y el intercambio de palabras y de acciones. Los griegos, al interior de la Polis, como espacio que se comparte, tenían además el ágora, donde los hombres libres participaban, debatían, actuaban y tomaban decisiones; eran la palabra -lexis- y la acción -praxis- las que se fundían para dar sentido a la organización del pueblo en torno al ágora, un espacio que garantiza la memoria de los actores y que garantiza a cada uno de los ciudadanos y políticos que sus acciones y palabras serán perdurables; pero para que esto suceda, los hombres tendrán que vivir junto a otros hombres y dejar los espacios de "Solitud" para vivir junto a sí mismo, como el dos en uno socrático, que le permite a los individuos pensar y reflexionar, como una acción que prepara también para el espacio público.

\section{Republicanismo y Participación Ciudadana}

Es necesario por lo menos mencionar los dos grandes enemigos de la libertad política, los que a su vez justifican la posición republicana defendida por Arendt. El imperialismo y el Totalitarismo son los dos grandes enemigos, por excelencia, de la libertad política. Por su parte, se sabe que el imperialismo tuvo como objetivo la expansión económica por fuera del Estado-Nación y cuya competencia significó (2006, p. 214) por una parte, la victoria comercial de unos y la muerte de los demás y por otra parte, la desnacionalización como elemento desintegrador del Estado-Nación, donde cada individuo se convirtió en extranjero, paría, apátrida o víctima de un sistema que lo fue dejando poco a poco sin derechos. De este modo el imperialismo trajo como consecuencia que muchas personas perdieran la protección de sus gobiernos y se convirtieran en caldo de cultivo del Totalitarismo. En este sentido, el imperialismo fue la base a partir de la cual el Totalitarismo hizo su entrada triunfal en el siglo XX con el objetivo fundamental, no de organizar a las clases sino a las masas (Arendt, 2006, p. 435), pues las masas no se mantienen unidas por la conciencia de un interés y carecen de esa clase específica de diferenciación. El termino masa, dice Arendt:

Para $\quad$ Franco Gaviria, Luis Horacio (2013). El Concepto de libertad política en Hannah Arendt. 
Se aplica sólo cuando nos referimos a personas que, bien por su puro número, bien por indiferencia, o por ambos motivos, no puede ser integrada en ninguna organización basada en el interés común...potencialmente existen en cada país, y constituyen la mayoría de esas numerosas personas neutrales y políticamente indiferentes cuyo futuro muestra la pérdida de interés por sí mismos y por los demás, pues el hombre masa ha sido privado de mucho más que las cadenas de la miseria cuando perdían el interés por su propio bienestar (2006, p. 438).

De esta manera, el gran triunfo del imperialismo fue la restricción de la libertad política y del Totalitarismo su abolición.

\section{E1 Republicanismo}

En líneas generales, el Republicanismo se remonta a la Roma clásica de Cicerón, con una fuerte influencia en el pensamiento de Maquiavelo, Montesquieu y de Toqueville y con una menor aproximación al pensamiento republicano se encuentran Rousseau y Kant. La tradición republicana se ve debilitada con la aparición del liberalismo como una filosofía que interpretaba de mejor forma el mundo moderno y aunque en principio retomó algunas ideas republicanas, rápidamente se separó de sus líneas para disfrutar de sus libertades individuales y perseguir sin interferencias su instinto comercial. Entender las diferencias entre estas dos tradiciones permite, por un lado, ubicar contextualmente la discusión contemporánea de la libertad, la que a su vez, trae al diálogo la distinción que hace Isaiah Berlin (1958) sobre la libertad negativa y la libertad positiva o la discusión de Benjamín Constant (1988) sobre la libertad de los antiguos y la libertad de los modernos y por otro lado, entender con mayor claridad el concepto de libertad política en Arendt, que se inscribe con claridad en el neorepublicanismo.

Para recordar, la libertad negativa consiste en estar libre de la interferencia de otros y de esta manera pensar lo que se quiera, hablar como se quiera y con quien se quiera, moverse por donde se quiera, entre muchas otras libertades individuales. Por su parte, la libertad positiva necesita mucho más que esto; se trata de la participación en comunidad que permita superar no sólo los obstáculos internos como la razón, la voluntad y las pasiones, sino también los obstáculos externos impuestos por los demás en el claro intento de una convivencia pacífica. La participación trae poder y seguridad a cada uno de los individuos y cierto perfeccionamiento moral que apunta a un mayor grado de civilidad y mejores condiciones de vida.

Desde esta perspectiva, la libertad positiva se asocia a la libertad de los antiguos, mientras que la libertad negativa está ligada a la modernidad. A pesar de que son 
muchos los autores que apuntan a que desde la antigua Roma ya existían indicios de una defensa de la libertad negativa, en el sentido de defender las leyes, no como un ideal democrático, sino con la intención de una protección individual. Es decir, que todas las garantías públicas e institucionales debían estar en función de la seguridad privada de los individuos y el resguardo de sus propiedades ¿Cuál es la diferencia entre la libertad de los republicanos y la libertad de los liberales si es que ambos están de acuerdo en brindar seguridad a los individuos y en defender sus derechos? La respuesta, desde Petit (1999) es que mientras los liberales igualan la libertad con la ausencia de interferencia, los republicanos la equiparan con estar protegidos contra la exposición a la interferencia voluntaria de otro, es decir, estar seguro contra tal interferencia. Libertad, en este sentido equivale a no estar bajo el poder que tiene otro de hacer daño, en otras palabras, a no estar dominado por otro.

La libertad, como no dominación - la libertad como seguridad contra la interferencia arbitraria- es un ideal completamente diferente de la libertad como estricta interferencia. La dominación es la clave de la relación ejemplificada por el vínculo entre el amo y el esclavo o entre el amo y el sirviente.

Los republicanos, tradicionalmente, han insistido en oponer la libertad a la dominación o la esclavitud, ya que en esta relación, cuando una voluntad arbitraria domina a otra, significa tener que vivir de acuerdo con la voluntad de otro; de alguna manera muy especial, los republicanos aceptan que puede haber interferencia sin dominación y seguir gozando de libertad. Específicamente, en el caso de las leyes, puede haber interferencia, pero para garantizar mayor libertad y mayor seguridad. Diferente resulta la mirada de muchos de los liberales que al pensar en la libertad como no interferencia, piensan que las leyes son una especie de invasión a la libertad y por lo mismo, las restricciones impuestas por las leyes, son restricciones impuestas a la libertad.

\section{Conclusiones}

En líneas generales Arendt se inscribe en la tradición republicana, pero con algunos matices que ella misma va construyendo a través de sus escritos, especialmente en Sobre la Revolución, Crisis de la República y La Condición Humana. ¿Cuáles son esos matices? Salvador Giner (2006) en el prólogo a Orígenes del Totalitarismo los menciona con claridad:

El ciudadano participativo no se ciñe a lo político sino sobre todo a la actividad en la esfera compartida de la convivencia. Tampoco se confunde con el

Para $\quad$ Franco Gaviria, Luis Horacio (2013). El Concepto de libertad política en Hannah Arendt. 
militante, a quien absorbe la militancia hasta agotar su criterio independiente y la distancia necesaria que debe poseer el buen ciudadano frente a toda obediencia ciega (...) Hay, un republicanismo dogmático, peligroso, de inclinación totalitaria, que evoca sin pudor al "hombre nuevo", ensalza al tirano y quiere forzar a las gentes a la pureza política. Y hay otro cívico, paciente, incapaz de perder la fe en el buen sentido de la ciudadanía y que desea la libertad de cada cual. A ese pertenece la posición de Hannah Arendt, que fundamenta su concepción republicana sobre la acción compartida, no sobre la solitaria, ni tampoco sobre la multitudinaria, en el espacio público. (pp. 22-23).

Así, el matiz republicano de Arendt es antiliberal, pues considera que el liberalismo es incapaz de comprender la sociedad con todos los cambios tecnológicos y económicos surgidos en la modernidad. A modo de ejemplo, los republicanos tienen la idea firme de que las leyes deben proteger y promover la libertad de los individuos, mientras que la conexión de los liberales con las leyes se da para la protección de la propiedad ya que es la propiedad y no la ley la que garantiza la libertad. El liberalismo ha invertido el principio de protección; si bien antes, en las monarquías, era muy importante el consentimiento de los súbditos, lo que se impone con los liberales, se insiste, es el derecho de propiedad. Para el siglo XVIII y también para el XIX: "La función de las leyes no consistían primordialmente en garantizar un cierto número de libertades, sino en proteger la propiedad, era la propiedad y no la ley la que garantizaba la libertad...quien decía propiedad decía libertad y la recuperación o la defensa de los derechos de propiedad del individuo, se identificaban con la lucha por la libertad" (Arendt, 2009, p. 247).

Por su parte Canovan (1992, p. 201) cree que el Republicanismo de Arendt se resume en tres líneas fundamentales: la primera, es reconocer que a partir de los desarrollos científicos los seres humanos están en peligro y que de forma aislada cada ser humano es muy vulnerable, por lo que se hace urgente recuperar las instituciones y los cuerpos políticos que garanticen la permanencia de la vida humana; la segunda, es que a pesar de la deficiente comprensión del peligro de la tradición liberal, hay que entender que los seres humanos son plurales y que se deben crear y proteger los espacios donde la pluralidad se manifieste; y por último, el Republicanismo tiene que ser una respuesta a los horrores del Totalitarismo, no desde la moral individual, sino desde el espacio público, que se construye "entre" los hombres de acción.

Con lo anterior, es decir, con el matiz antiliberal que Arendt le da al neore158 publicanismo y con la defensa de Republicanismo en contra del Totalitarismo, 
la libertad política emerge como una reflexión que le devuelve el sentido a la política y posibilita nuevas rutas de acceso a la comprensión de la modernidad, pues según Arendt, la modernidad es mucho más amplia de lo que la historia misma ha podido ver en ella y en consecuencia, las bases del Republicanismo arendtiano no necesariamente se quedan en la polis griega sino que admite otras sociedades y trae a su reflexión otras experiencias ciudadanas.

La más importante experiencia es la libertad política, calada en un espíritu agonal, donde todo individuo, en su lucha constante por la libertad política anti-dominación o anti totalitaria, lucha por ser él mismo en medio de los movimientos totalitarios que organizan y generan las grandes masas, aquellas en las que el individuo se pierde totalmente y deja a un lado sus preocupaciones por sus intereses particulares y se entrega a la consecución de los objetivos del líder totalitario, quien con magistral habilidad ha transformado la realidad de los individuos al convertir la mentira en verdad y lograr a todo precio el cumplimiento de sus profecías (Arendt, 2006, p. 485).

Desde esta perspectiva, la libertad política de Arendt, en la República, se posa entre dos grandes críticas ya descritas; por un lado, la libertad negativa de los liberales que pusieron por encima de la vida los intereses mismos de la propiedad y por otro lado, los movimientos totalitarios que borran de la Polis al individuo y lo convierten en hombre masa, sin identidad y sin valoraciones distintas a las del líder totalitario.

Lo que se deduce es que la libertad política en Arendt va más allá de las leyes y las instituciones, pues no sólo busca los espacios para el desarrollo de cada individuo, sino que propicia la participación con los demás, como la fuente de la reconstrucción de la esfera pública. Sin más, se trata de una libertad positiva para la participación plural, diversa, innovadora, espontánea y renovadora; reconocida en un espacio común construido entre iguales; no sólo iguales en derechos, sino también iguales en oportunidades y posibilidades de participación.

Sin embargo, este gran sueño, tiene condiciones y es la preparación de cada ciudadano para ejercer su libertad política en un espacio público. ¿Qué significa y en qué consiste dicha preparación? Si se acepta con Canovan (1992, p. 203) que la República es una organización política de la comunidad libre, es decir, en la que la cosa pública es posesión de los propios ciudadanos y no está bajo el dominio de otra comunidad política o de un señor al que se sirve, se debe entender que la responsabilidad de cada ciudadano, no sólo para reclamar su derecho a la libertad, sino para ejercer la libertad política y protegerla de todos los que atente contra ella, es muy alto y por lo mismo cada ciudadano se prepara para asumir 
tan dura tarea. De esta manera, la libertad política en la República supone la presencia de hombres virtuosos capaces de responder por sus actos, asumir las consecuencias y trabajar por el bien común.

\section{Referencias}

Amiel, A. (2007). Hannah Arendt. Buenos Aires: Atuel.

Arendt, H. (1996). Entre el pasado y el futuro. Ocho ejercicios sobre la reflexión política. Barcelona: Ed. Península.

Arendt, H. (2005). La condición Humana. Barcelona: Paidós.

Arendt, H. (2005). De la bistoria a la acción. Buenos Aires: Paidós.

Arendt, H. (2006). Los Origenes del Totalitarismo. Madrid: Alianza Editorial.

Arendt, H. (2007). ¿Qué es la política? Buenos Aires: Paidós.

Arendt, H. (2007). Responsabilidad y Juicio. Barcelona: Paidós.

Arendt, H. (2007). Karl Marx y la tradición del pensamiento político de occidente. Madrid: Ediciones Encuentro.

Arendt, H. (2008). La promesa de la Politica. Barcelona: Paidós.

Arendt, H. (2008). Sobre la violencia. Madrid: Alianza editorial.

Arendt, H. (2009). Sobre la revolución. Madrid: Alianza editorial.

Arendt, H. (2010). La vida del espíritu. Buenos Aires: Paidós.

Canovan, M. (1992). Hannah Arendt: A reinterpretation of her political Thought. Cambridge. University Press.

Gauss, G. (1964). Conversación con Hannah Arendt. Una mirada sobre el segle. Nomesem queda la lengua materna. Recuperado de http://www.alcoberro.info/pdf/ arendt4.pdf

Sánchez, C. (1994). Paria o Ciudadana del mundo. En C. Manuel, En torno a Hannah Arendt. Madrid: Centro de estudios Constitucionales. 